\title{
ACUTE SPINAL EPIDURAL ABSCESS
}

\author{
By R. N. Hakin, M.R.C.P. (Senior Registrar in Neurology), \\ A. A. BURT, M.R.C.P. (Consultant Neurologist) and \\ J. B. Cook, M.D., F.R.C.P. (Consultant Neurologist) \\ Department of Neurology and the Yorkshire Regional Spinal Injuries Centre, \\ Pinderfields General Hospital, Wakefield
}

\begin{abstract}
Case Report
A 25-YEAR-OLD male teacher, ironically, of disabled children, presented on 18 November I 977 to his local casualty department complaining of pain in the mid-dorsal region which had been present for 2 weeks. He described it as 'extremely severe' and found that the two most comfortable positions were standing upright or in a slightly flexed prone position over some cushions; it was extremely painful to be on his back. The pain was aggravated by coughing, sneezing and straining at stool and tended to radiate round to the front of the upper abdomen. The only finding of note was some tenderness over the spines of D8, 9 and Io. His dorsal and lumbar spines and pelvis were X-rayed and found to be normal. He was sent home with a prescription for some simple analgesics.

Over the next 5 days he consulted his General Practitioner who thought that he might have rheumatism and prescribed a short course of steroids. The pain, however, became worse and on 23 November 1977 he reappeared in the same casualty department. In addition to his now 'excruciating' back pain he was complaining of constipation of one week's duration and a feeling that his legs were 'weak and wobbly', but there were no sensory symptoms and bladder function was normal. He was again X-rayed with normal results, and was again tender in the dorsal region, with no other abnormal findings, and was given an enema and discharged. On the evening of 23 November 1977 he noticed progressive weakness of both legs together with intermittent pins and needles and numbness extending up to the umbilicus. On awaking the next morning he was unable to move his legs, he felt numb up to the waist and his own doctor found a palpable bladder extending up to the umbilicus. On arrival at his local casualty department for the third time he was found to have a flaccid paralysis of both legs, a bladder distended to the umbilicus, and a complete loss of sensation from D9 with a crisp sensory level. A catheter was inserted and he was transferred to the Neurological Unit at Pinderfields General Hospital, Wakefield, with a diagnosis of cord compression.

$\mathrm{He}$ arrived at 5.00 p.m. on 24 November 1977 and we noted the flaccid paralysis and sensory loss with absent reflexes in the legs and no plantar response. There was a catheter in situ.

In addition we noticed a small scar on the right buttock. The patient then disclosed that he had had a staphylococcal abscess drained I month previously. We performed an immediate myelogram and this showed (Fig. I) an extradural block at the lower border of D9. He was taken to theatre and an exploratory laminectomy revealed $10 \mathrm{ml}$ of thick greenish pus in the extradural space extending from D8 to Dio and involving the lamina of D9. In addition there was granulation tissue compressing the theca in this region; this was removed piecemeal. Staphylococcus aureus was isolated from the pus.

He made a good postoperative recovery but unfortunately there was no improvement in his neurological state, he remained completely paralysed from the waist with no return of bladder function and a complete loss of sensation. He was transferred to the Spinal Injuries Unit for rehabilitation but on I December I 977 collapsed following a massive pulmonary embolus and died I hour later. The autopsy report, in addition to confirming a large pulmonary embolus, was as follows:
\end{abstract}




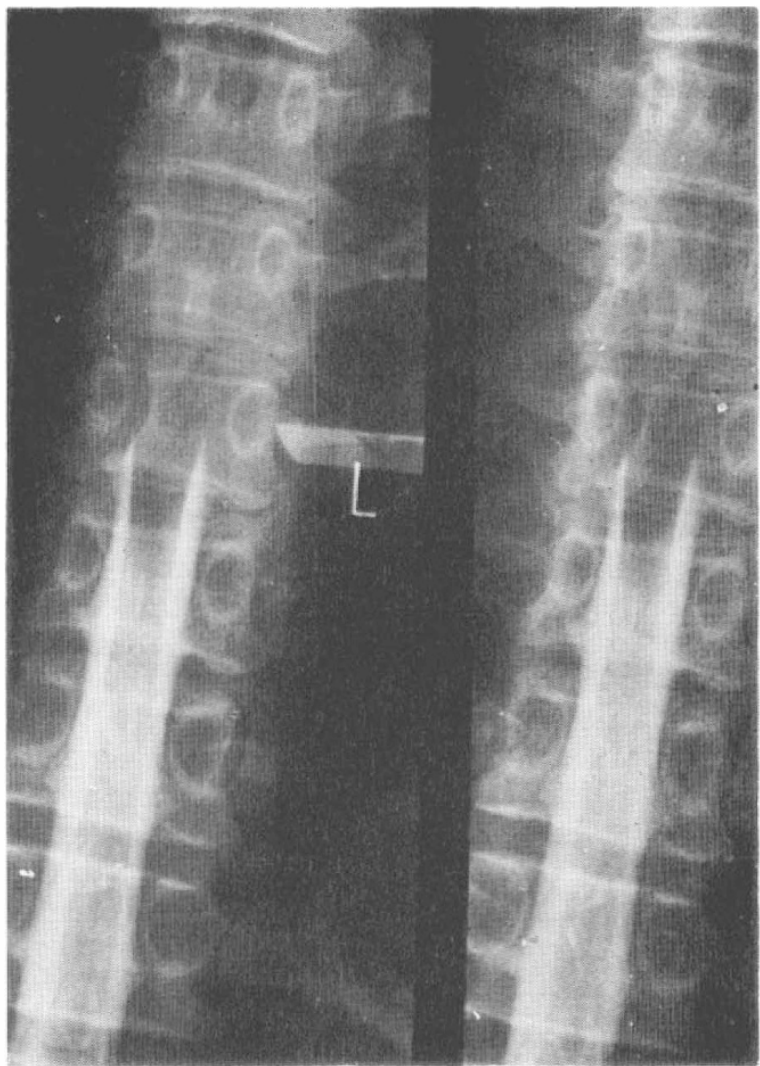

FIG. I

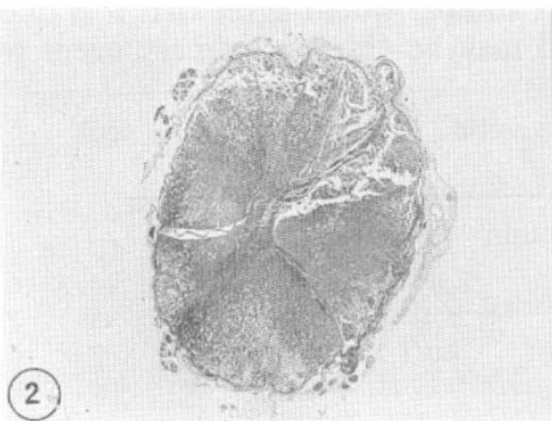

FIG. 2

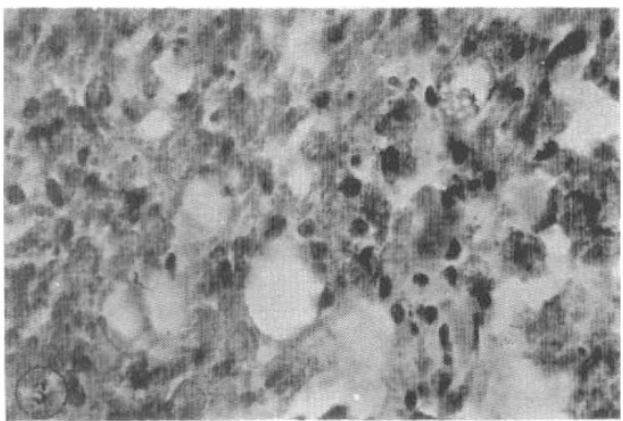

FIC. 3

'The major pathology lies at the level of Tio section where there has been extensive destruction, predominantly of white matter, involving both lateral columns, and predominantly superficial zones within the dorsal columns. There is sparing at this level of both anterior horns and a small amount of surrounding white matter is also unaffected. The destruction is in the form of myelin loss and the aggregation of relatively small numbers of lipid-laden macrophages together with degenerative changes in adjacent neurones. The neurones, within the nucleus dorsalis show patchy chromatolyosis, but 
the degree of obstruction is relatively mild in these areas. The extensive destruction observed at this level suggests either severe compression of more probably the effects of compression of a supplying artery or arteries. One or two small blood vessels in the dorsal columns show perifascular cuffing by lymphocytes and small numbers of lymphocytes are seen migrating into adjacent necrotic white matter but polymorphs are strikingly absent. In the ascending columns proximal to, and the descending columns distal to the Tio level there is remarkably little in the way of Wallerian degeneration apparent. There are occasional swollen axons but unequivocal evidence of myelinoclasis and free lipid accumulation is lacking, although the localization of the damage suggests interference with blood supply. The vessels in the sections examined show no evidence of venous or arterial thrombosis. There is no evidence of suppuration within the cord (Figs 2 and 3).

\section{Discussion}

As many authors have pointed out it is absolutely essential to make the diagnosis of spinal epidural abscess as early as possible-the case report shows this in a striking and tragic fashion-and we therefore reviewed the series of patients seen in Pinderfields General Hospital over the last 20 years to ascertain if there were any clues which would make the diagnosis easier. It is, of course, possible to make the diagnosis only if it is thought of.

There were twelve patients in all (Table I) with an age range of 13 to 37 years, the average age being 22 years. This is younger than in many series (Heusner I948, Hancock I973), but this is almost certainly due to the fact that many were referrals to a spinal injuries unit. The sex distribution was nine males to three females. Adding together the patients from papers by Heusner, Hancock and others we found that the male/female ratio was almost exactly I : I.

The presenting symptom is very important. It is almost invariably back pain and is characteristically described as 'very severe' or 'excruciating'. Allowing for the many neurotics who may exaggerate their low back pain there seems no doubt that the back pain of an epidural abscess is quite different from the low back pain of 'rheumatism', 'lumbago' or many of the other unidentifiable and non-specific causes of low back pain. Most authors would agree that it is due to osteomyelitis of the involved vertebrae and may be either a primary event with

TABLE I

\begin{tabular}{rrllc}
\hline & Age & Sex & First symptom & $\begin{array}{c}\text { Duration incomplete } \\
\text { paralysis }\end{array}$ \\
\hline I & I7 & M & Back pain & Io days \\
2 & I7 & F & Back pain & 3 days \\
3 & I2 & M & Back pain & 2 days \\
4 & 35 & M & Back pain & I 4 days \\
5 & 20 & F & Back pain & 10 days \\
6 & 33 & M & General malaise & 30 days \\
7 & I4 & F & Back pain & 4 days \\
8 & 31 & M & Back pain & 2 days \\
9 & 37 & M & Root pain & 5 days \\
I0 & I9 & M & Back pain & I day \\
I I & 25 & M & Back pain & 2I days \\
I2 & I3 & M & Back pain & 2 days \\
\hline
\end{tabular}


spread from the bone to the extradural space or due to secondary spread from the extradural abscess. Of our patients only two did not present with back pain; one presented with root pain and the other with general malaise, a low-grade pyrexia and loss of weight; it turned out later that he had been taking a broad spectrum antibiotic at the start of the illness which may have influenced the course of the disease and the presenting symptoms.

The point in question is whether it is possible to make the diagnosis early enough to prevent the patient suffering permanent paralysis.

As Heusner (1948) first suggested, if the paralysis has been present for less than 24 hours the chances of either complete or partial recovery are good; if the paralysis has been present for more than 36 hours the prognosis is poor. The last column (Table I) shows the time between the first symptoms (back pain) and the onset of complete paralysis. This varied between I and 30 days, the average being 9 days. However, there were two patients in whom there was a delay of $2 \mathrm{I}$ days and 30 days and excluding these two patients the average delay between the first symptom and the onset of complete paralysis was $5 \frac{1}{2}$ days.

If the patient does not present to a doctor the opportunities for diagnosing a potentially remediable condition will be considerably reduced. We checked the records to find out how long it took each patient to present to a doctor for the first time (Table II). There is no doubt that almost invariably the patient presents for the first time within 24 or 48 hours. Of the I 2 patients only two did not do so; one, a young boy in whom an initial diagnosis of poliomyelitis had been made, presented at 9 days and in the second case (case report) the patient presented at I4 days-probably more a reflection of his stoicism than of the insignificance of his pain. The other interesting feature of this table is the non-specificity of the initial diagnosis - it varied from 'fibrositis', 'pulled muscle' and 'rheumatism' to 'muscular pain' and 'disc lesion'. One patient (No. 9) was diagnosed as having a chest infection when in fact his symptoms were due to root pains at the $\mathrm{D}_{7}$ level. In only one case was a diagnosis of cord compression made at initial presentation and

\section{TABLE II}

\begin{tabular}{|c|c|c|c|c|}
\hline & Age & Sex & Initial diagnosis & $\begin{array}{l}\text { Duration of symptoms } \\
\text { before consulting doctor }\end{array}$ \\
\hline I & 17 & $M$ & Fibrositis & I day \\
\hline 2 & I7 & $\mathrm{F}$ & Pulled muscle & I day \\
\hline 3 & I 2 & $\mathrm{M}$ & ? Poliomyelitis & 9 days \\
\hline 4 & 35 & $M$ & Muscular Pain & 2 days \\
\hline 5 & 20 & $\mathrm{~F}$ & $\begin{array}{l}\text { Disc lesion, referred to orthopaedic } \\
\text { surgeon (traction) }\end{array}$ & $\begin{array}{l}\text { I day } \\
\text { I day }\end{array}$ \\
\hline 6 & 33 & $M$ & $\begin{array}{l}\text { Disc lesion, referred to orthopaedic } \\
\text { surgeon (traction) }\end{array}$ & 2 days \\
\hline 7 & I4 & $\mathrm{F}$ & Muscular pain & 2 days \\
\hline 8 & $3 I$ & $\mathrm{M}$ & $\begin{array}{l}\text { Disc lesion, referred to orthopaedic } \\
\text { surgeon }\end{array}$ & 2 days \\
\hline 9 & 37 & $M$ & Chest infection & 2 days \\
\hline Io & 19 & $M$ & Rheumatism & I day \\
\hline II & 25 & $M$ & Rheumatism & I4 days \\
\hline 12 & 13 & M & Cord compression & I day \\
\hline
\end{tabular}


TABLE III

Post Operative Outcome of Spinal Epidural Abscess

\begin{tabular}{|c|c|c|c|}
\hline Good recovery & 2 & 3 & 6 \\
\hline Partial recovery & Ely & 4 & 7 \\
\hline No recovery & \{ & & $\begin{array}{l}9 \\
121 \\
12\end{array}$ \\
\hline
\end{tabular}

in spite of the early diagnosis and immediate decompression the patient failed to make any recovery at all.

The conclusions from Tables I and II therefore are that firstly the doctor to whom the patient initially presents has approximately 5 days in which to make the diagnosis and that unless he does so the chances of the patient recovering or preserving function below the level of the lesion are greatly reduced. Secondly the two significant presenting symptoms, which must not be overlooked, are 'excruciating' back pain and very marked tenderness over the corresponding vertebral spines.

The outcome in these patients is seen in Table III. It is necessary to define the terms 'good recovery', 'partial recovery' and 'no recovery'. By 'good recovery' we mean that the patient can walk unaided or with the use of a walking stick and that sphincter control is complete or nearly so. 'Partial recovery' signifies that the patient needs calipers and or crutches and that sphincter control is variable. 'No recovery' means what it says; complete paralysis and loss of sensation below the level of the lesion and absent sphincter control. As Heusner (I948) pointed out, if the paralysis has been present for less than 24 hours it is likely that there will be some recovery; if it is greater than 36 hours then it is most unusual for there to be any return of function. This general rule certainly applied to our patients although there were exceptions. The young man in our case report had been paralysed for less than 24 hours and yet he showed no signs of recovery whatsoever; another patient in the series had been completely paralysed for 3 days and yet made a partial recovery; the fact that he had been on large doses of an antibiotic may be significant. We wondered, therefore, if there were any other prognostic criteria that could be applied pre-operatively. One fact that emerged from our review was that some patients had a complete loss of sensation below the level of the lesion with a crisp sensory level whilst others had either no loss of sensation or only patchy sensory disturbances. As can be seen from Table III those patients with complete loss of sensation (shaded area) with one exception (patient No. I) made no recovery at all whilst those patients with partial or no sensory loss (unshaded area) made either a partial or good recovery. In addition to Heusner's 


\section{TABLE IV}

HISTOGRAM SHOWING VERTEBRAL LEVEL OF

SPINAL EPIDURAL ABSCESS

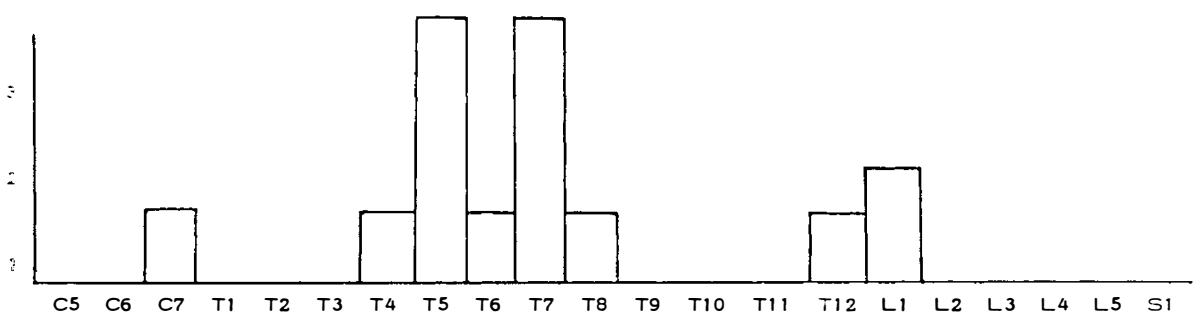

24-hour rule we suggest that the extent of the sensory disturbance may be used as a prognostic indicator. These are not absolute rules because if the onset of cord compression is slow, e.g. over many days or in the case of benign tumours weeks, months or years, then there may be substantial recovery even though the patient has been paralysed for some considerable time. An acute spinal epidural abscess, however, does not damage the cord by compression alone; as the abscess expands it is said to occlude the smaller vessels partly by direct pressure and partly by an end-arteritic process. This is said to be the explanation for the acceleration of the symptoms, well illustrated in our case report, over a period of a few hours. Browder and Meyers (I94I) described nine patients who came to autopsy and although they found the occasional vessel occluded by thrombus, this was rare and more often they were 'unaltered or congested'.

We examined our sections of the cord very carefully and did not find any vessel actually occluded by thrombus, although many small vessels showed perivascular cuffing by lymphocytes with lymphocytic migration into the cord. We do not believe, therefore, that the pathological mechanism for the accelerated phase during which the neurological symptoms start and may become permanent within a few hours, is fully worked out.

The last table (Table IV) is a histogram showing the distribution of the levels at which spinal epidural abscesses occurred. Although the numbers are small it shows quite clearly the large peak between $\mathrm{D}_{4}$ and D9 and the smaller peak in the upper lumbar region. The explanation for the predilection of spinal epidural abscesses for these two sites is said to be as follows:

In most regions of the spinal canal the dura is closely adherent to the vertebral bodies anteriorly and the laminae posteriorly together with the appropriate ligamentous structures. In two regions, however, the extradural space is expanded thereby giving any focus of infection, whether it is in the extradural space itself or in an adjacent vertebra, the opportunity to expand and form an abscess. Between $\mathrm{D}_{4}$ and D9 it is expanded posteriorly and laterally to the cord and below $\mathrm{LI}_{\mathrm{I}}$ it is similarly large with the expansion, in addition, extending anteriorly around the cord. A further point is that although in the table one vertebral level represents one patient, spinal epidural abscesses are no respectors of histograms; the usual length of a spinal epidural abscess is three or four segments and in addition there 
may be more than one abscess in any one patient. One of our patients had an abscess at $\mathrm{L}_{\mathrm{I}}$ and a second abscess at $\mathrm{C}_{7}$.

Acute spinal epidural abscess is a rare disorder. The practitioner to whom the patient presents will in all probability never have seen a case before. It behoves us as teachers to increase awareness of the disorder and particularly its natural history in order that earlier diagnosis may be achieved more often and the chances of good functional recovery improved.

\section{SUMMARY}

A case of acute spinal epidural abscess is reported demonstrating many of the important features in the natural history of the disorder. The pathological changes in the cord at the level of the lesion are described. A series of 12 patients is reviewed. The average interval between the initial consultation and the onset of complete paralysis is 5 days and it is essential that the diagnosis is made during this period. Two indicators of prognosis are discussed-the duration of complete paralysis and the extent of sensory disturbance.

\section{RÉSUMÉ}

Les auteurs présentent un cas d'abcès aigu extradural de l'épine dorsal, qui manifeste plusieurs caractéristiques importantes du désordre.

Les changements pathologiques de la moelle épinière au niveau de la lésion sont presentés.

Douze cas sont passés en revue. On a trouvé que l'intervalle moyen entre la première consultation et la paralysie total est cinque jours, et que c'est essentiel qu'on diagnostique la maladie pendant ce temps.

Deux indices du prognostic sont discutés: la durée de la paralysie totale, et l'étendue du dérangement sensoriel.

\section{ZUSAMMENFASSUNG}

Ein Fall von einem akuten Epiduralabszess des Rückenmarks wird beschrieben, welcher viele der wichtigen Merkmalen in der charakteristischen Entwicklung der Krankheit vorweist. Die pathologischen Veränderungen in dem Rückenmark zur Höhe der Läsion werden beschrieben. Eine Gruppe von zwölf Patienten wird überschaut. Die Durchschnittszeit zwischen dem ersten Konsultation und Anfang der vollständigen Paralysie ist fünf Tagen und es ist durchaus notwendig, dass die Diagnose während dieser Zeit gestellt ist. Zwei Indikatoren der Prognose werden behandelt-die Dauer der vollständigen Paralysie und die Ausdehnung der Empfindungsstörung.

\section{REFERENCES}

BAKer, C. J. (197I). American fournal of Diseases in Children, I21, 337.

BROWDER, J. \& MEYERS, R. (1937). American fournal of Surgery, 37, 4.

BROWDER, J. \& MEYERS, R. (I94I). Surgery, I0, 296.

CoHEN, I. (1938). Annals of Surgery, 108, 882.

DANDY, W. E. (1926). Archives of Surgery, Chicago, 13, 477.

HanCoCK, D. O. (1973). Paraplegia, 10, 285-288.

Heusner, A. P. (1948). New England Fournal of Medicine, 239, 845.

Hulme, A. \& DotT, N. W. (1954). British Medical fournal, $\mathbf{1}, 64$.

StAMMERS, F. A. R. (1938). British Fournal of Surgery, 26, 366. 